\title{
Electrical and Thermal Characterization of YBCO Coated Conductors for Resistive Fault Current Limiter Applications
}

\author{
Carlos A. Baldan, Carlos Y. Shigue, and Ernesto Ruppert Filho
}

\begin{abstract}
Electrical and thermal characteristics of Yttrium Barium Copper Oxide (YBCO) coated conductors (CCs) with different architectures, with and without stabilizer layers, in resistive fault current limiters (RSFCLs) have been widely studied. In this study, the recovery of the superconducting state under different conditions (no-load and under load) is analyzed for subsequent fault current limitation. Test of modular RSFCL using commercial coated conductor with and without the assistance of an air-core power reactor was carried out. Shunt-assisted quench tests were investigated and measurements have been performed in short samples employed in the construction of modular unit with 6 stacks of $0.7-\mathrm{m}$ length of 12-mm width YBCO CC tapes. Using the pulsed current method (PCM), the quench current (from Ic up to $3 \times$ Ic) for a time period from 16.6 to $80 \mathrm{~ms}$ was applied to evaluate the temperature and recovery time, by the power losses, generated after the second quench in sequence. The RSFCL operates in a distribution grid protected by a recloser switch with intervals of $300 \mathrm{~ms}, 900 \mathrm{~ms}$, and $1.2 \mathrm{~s}$. For these time intervals, it is necessary to verify if full recovery behavior happens.
\end{abstract}

Index Terms-Current limiting ratio, recovery time, superconducting fault current limiter, YBCO coated conductor.

\section{INTRODUCTION}

$\mathbf{T}$ HE resistive type of superconducting fault current limiter (RSFCL) based on Yttrium Barium Copper Oxide (YBCO) coated conductors (CCs) tape provides a solution to deal with the increasing incidence and level of fault currents with additional contribution to improving the performance, the stability, and the efficiency of electricity grids. The higher meshing of distribution networks and the integration of fast growing renewable energy sources lead to an increase in the fault current level with every new installation thus demanding RSFCL devices, which present no resistance during normal operating conditions and a large and quickly generated resistance

Manuscript received August 12, 2014; accepted December 24, 2014. Date of publication January 20, 2015; date of current version February 27, 2015. This work was supported in part by the Companhia Paulista de Força e Luz (CPFL), CNPq, FAPESP and CAPES.

C. A. Baldan is with the Escola de Engenharia de Lorena, Universidade de São Paulo-EEL/USP, 12602-810 Lorena-SP, Brazil, and also with the Departamento de Engenharia Elétrica, Universidade Estadual Paulista UNESP, 12516-410 Guaratinguetá-SP, Brazil (e-mail: cabaldan@ demar.eel.usp.br).

C. Y. Shigue are with the Escola de Engenharia de Lorena, Universidade de São Paulo-EEL/USP, 12602-810 Lorena-SP, Brazil.

E. Ruppert Filho is with the Faculdade de Engenharia Elétrica e Computação, Universidade Estadual de Campinas UNICAMP, 13083-852 Campinas-SP, Brazil (e-mail: ruppert@ fee.unicamp.br).

Color versions of one or more of the figures in this paper are available online at http://ieeexplore.ieee.org.

Digital Object Identifier 10.1109/TASC.2015.2390622 during fault conditions. The great number of substations limits the network capacity and the operators have to deny additional installations to the grids or presents the need to rebuild the substations completely. The RSFCL can be applied as a new tool for grid operation; they increase grid flexibility and are considered the most attractive superconducting device in comparison to the conventional system for current limitation, with selfrecovery in seconds and negligible impedance during operation. Leading industrial and academic institutions from Europe have designed, built, and tested several units of the 3 phase RSFCL using YBCO CC tape for worldwide applications, with a large number of electric utility companies participating in partnership [1]-[4].

RSFCLs can generate in milliseconds (without trigger) a fast transition resistance as it changes from the superconducting state to the normal state with high resistivity, normally until 5 cycles, thus limiting the fault current value by an order of magnitude, according to the design and circuit conditions. A superconducting device was designed taking into consideration the maximum allowed electrical field during 5 cycles, less than $80 \%$ of $E=50 \mathrm{~V} / \mathrm{m}$, and combining this restriction with limitation ratio desirable to define the conductor's length of the YBCO CC tape needed [5]-[8].

For medium class voltage applications, continuous long lengths of YBCO CC tapes are needed for building several modular units with series and parallel electrical connections [9]-[11]. For safety operations, RSFCLs can prevent damage to the circuit components within $50 \mathrm{~ms}$, this time interval being necessary for circuit breaker actuation. Nevertheless, for the electric utility companies, the desirable time must be increased to more than $1 \mathrm{~s}$, to permit the setting time in the recloser switch, unless there is instantaneous reclose for first action, after recovery of the superconducting properties in RSFCL. This extension on limiting time can be achieved by combining the modular superconducting device with an air core power reactor (ACPR) connected in parallel with the RSFCL to the grid line. The fast switch connected in series with the RSFCL must be opened 5 cycles after the fault current is detected to provide (under no-load condition) the recovery of the superconducting device. During the time after the RSFCL removal, the current should be still flowing through the ACPR to complete $1 \mathrm{~s}$ of current limitation to guarantee that the circuit breaker can be opened at the designed fault current value.

The commercial YBCO CC tapes with stainless steel reinforcement, 4-mm width (344S) and 12-mm width (Amperium), both supplied by the American Superconductor Inc. were used in this study. The high resistivity matrix $(\mathrm{Ni} 5 \% \mathrm{~W})$ that 


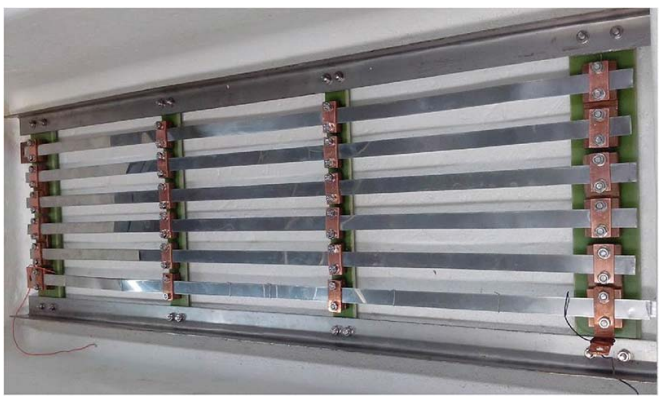

Fig. 1. Picture of the modular superconducting device constituted by $6 \times 0.7 \mathrm{~m}$ stacks of YBCO CC tapes connected in parallel with SS tape as external shunt.

contributed to increase the linear resistance from $0.075 \Omega / \mathrm{m}$ to $0.35 \Omega / \mathrm{m}$, respectively, was inserted for limiting the fault current level during certain time (less than $100 \mathrm{~ms}$ ) to a maximum allowable temperature of $350 \mathrm{~K}$ because of the fault current level reaching $10 \mathrm{kA}$. The recovery time was determined through the pulsed current method (PCM) on shortlength samples to avoid any irreversible tape degradation. An efficient cooling scheme should also be considered to expose the broad surface of the tape to the liquid nitrogen coolant. The temperature profile was calculated considering the evolution of resistance value in the YBCO CC tape.

Previous study reported the test results for RSFCL using two 25-m length YBCO tapes in parallel, with a shunt protection per element with equivalent resistance of $0.18 \Omega / \mathrm{m}$, totaling 24 sectors without tape splicing. This configuration provides a homogeneous quench behavior of the High Temperature Superconductors (HTS) tapes acting as stabilizer for the device [12]-[14].

Now, using a 12-mm width tape with double HTS layers with $I c=500 \mathrm{~A}$, the conceptual design for a $13.2 \mathrm{kV}$ line (7.6 kV phase-ground) will require 8 modular devices of $1 \mathrm{kV}$ connected in series with $\mathrm{YBCO}$ tape, each tape measuring 21.5-m in length $(E=46 \mathrm{~V} / \mathrm{m})$. A small-scale unit using $4.2 \mathrm{~m}$ tape length $(6$ stacks of $0.7 \mathrm{~m}$ ) for $220 \mathrm{~V}$ line for maximum rated current of $I=300$ A was built and tested using a stepdown transformer to supply the AC single phase-ground line voltage with an adjusted time for fault duration from 1 up to 5 cycles with maximum prospective fault current of $3.5 \mathrm{kA}$.

\section{SFCL PARAMETERS AND DESIGN}

The small scale RSFCL was constructed using the YBCO $\mathrm{CC}$ tape with stainless steel reinforcement of the American Superconductor's Amperium type 8612 double HTS layer, 12-mm width, 0.33-mm thick, with critical current, $I_{c}=500$ A (equivalent to a $416 \mathrm{~A} / \mathrm{cm}$ width). This tape, manufactured with Ni-5\%at.W substrate, has a linear resistance per length of $77.3 \mathrm{~m} \Omega / \mathrm{m}$ at room temperature.

The electric field that developed within the superconductor under safe condition can reach $50 \mathrm{~V} / \mathrm{m}$ ( 5 cycles fault current) with the shunt resistance of stainless steel tape $(0.6 \times 15 \mathrm{~mm}$ width), $R_{\mathrm{sh}}=74 \mathrm{~m} \Omega / \mathrm{m}$ or $R_{\mathrm{eq}}=37 \mathrm{~m} \Omega / \mathrm{m}$, reaching $R=$ $0.8 \Omega$ for the modular device with $21.5-\mathrm{m}$ length of YBCO tape.

The geometry of the modular superconducting device (Fig. 1) aims to expose all the surface of YBCO tape to the coolant with 6 stacks $(6 \times 0.7 \mathrm{~m})$ soldered at their ends to copper terminals. The modular unit was designed for operating at $220 \mathrm{~V}$ under a

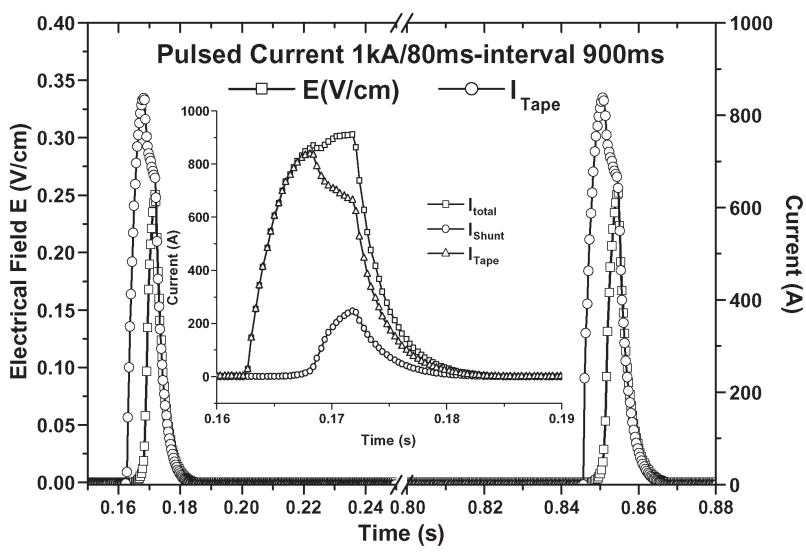

Fig. 2. Pulsed current test curve for $1 \mathrm{kA}$ during $80 \mathrm{~ms}$ with time interval of $900 \mathrm{~ms}$ before second pulse.

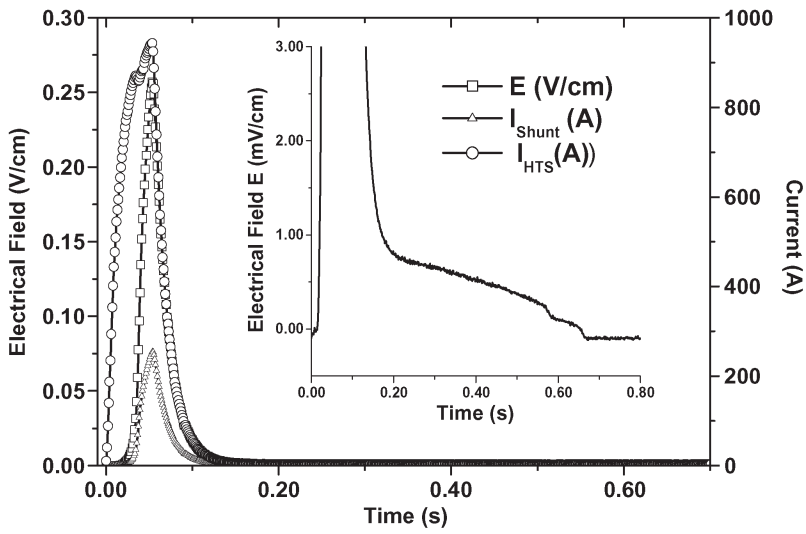

Fig. 3. Pulsed current test curve for $1 \mathrm{kA}$ during $80 \mathrm{~ms}$ with recovery time lower than $900 \mathrm{~ms}$.

steady current of 185 A to limit a prospective fault current of $2.5 \mathrm{kA}$.

The rated apparent power of the grid is given by $S_{r}=$ $\sqrt{ } 3 U_{r} I_{r}$ (three phase), where $U_{r}$ is rated voltage and $I_{r}=$ $I_{c} / \sqrt{ } 2$ is the rated current. The nominal power per area of the SFCL (single phase) can be calculated multiplying $U_{r} / \sqrt{ } 3 L$ by $I_{c} / \sqrt{ } 2 w$, where, $I_{c}$ the critical current, $L$ and $w$ are the conductor length and width, respectively, giving the nominal power of $37.3 \mathrm{kVA}$ for this unit, corresponding to a $\mathrm{rms}$ power value $74 \mathrm{VA} / \mathrm{cm}^{2}$ for fault duration varying from 50 up to $100 \mathrm{~ms}$ [12], [13]. The energy density $534 \mathrm{~J} / \mathrm{cm} 3$ is lower than the critical value of $1,200 \mathrm{~J} / \mathrm{cm}^{3}$ [14].

\section{ElectricAl PERFormanCE}

\section{A. Pulsed Current Characterization}

The short sample test was carried out for evaluating the resistance growth, temperature profile and the recovery time, using pulsed current of amplitude of up to 2.5 times $I_{c}$ with $0.1 \mathrm{~s}$ duration followed immediately after by a lower current value equivalent to $20 \% I_{c}$. The test result is presented in Fig. 2 for the 12-mm width tape of YBCO in parallel with a shunt protection. In the pulsed current curve, the electrical field reaches $0.25 \mathrm{~V} / \mathrm{cm}$ for $850 \mathrm{~A}$, corresponding to a resistance value of $R=30 \mathrm{~m} \Omega / \mathrm{m}$ and a recovering time after the current peak lower than $0.7 \mathrm{~s}$ (Fig. 3), whereas steady current was maintained at $20 \mathrm{~A}$. 


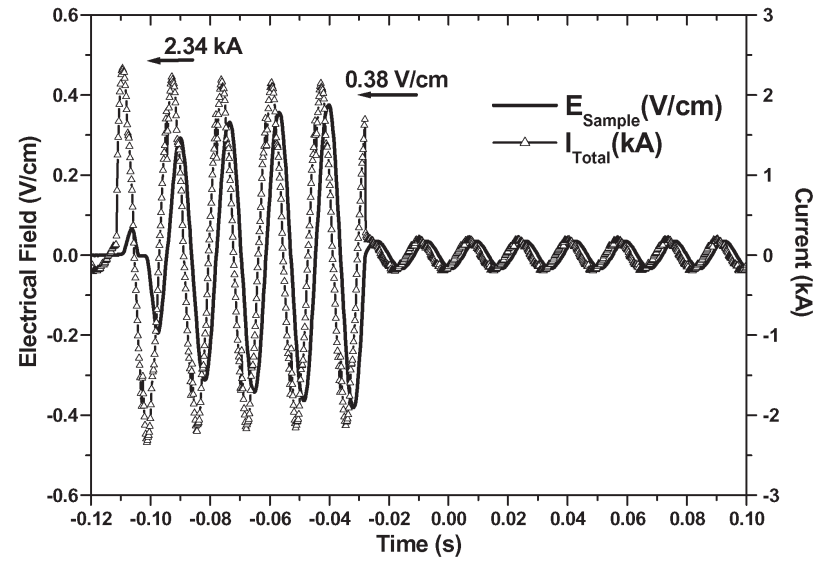

Fig. 4. Electrical field for YBCO tape (12-mm width) under fault current test of $2.5 \mathrm{kA}$.

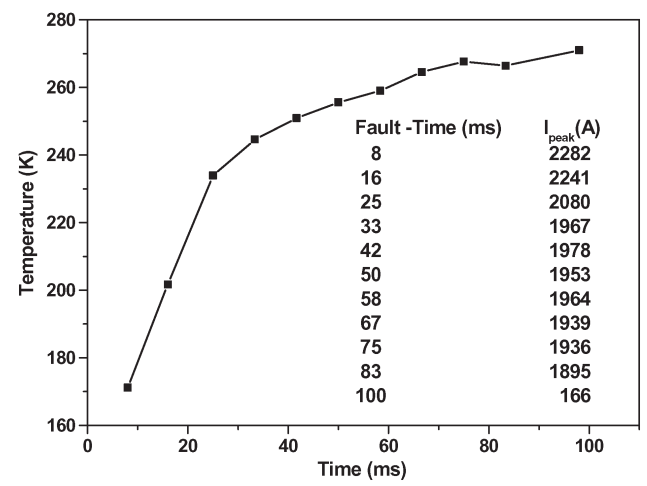

Fig. 5. Maximum temperature rise in the tape during the fault test.

\section{B. Short Sample AC Current Test}

Subsequent fault current tests were carried out in short sample of YBCO 12-mm-width tape using a step-down transformer of $40 \mathrm{kVA}-220 \mathrm{~V} / 20 \mathrm{~V}$, with fault current level of $3 \mathrm{kA}$ applied during $80 \mathrm{~ms}$ with a time interval of $1.2 \mathrm{~s}$. The maximum electrical field reached $E=0.38 \mathrm{~V} / \mathrm{cm}$ and the recovery time was measured under load condition for steady peak current of 185 A (Fig. 4).

Fig. 4 shows the waveforms for prospective fault current of $2.5 \mathrm{kA}$ during $80 \mathrm{~ms}$ with small limiting ratio in the shortsample test. For a fault current of $2.34 \mathrm{kA}$, the electrical field reached $E=0.38 \mathrm{~V} / \mathrm{cm}$ with recovery time of $1.5 \mathrm{~s}$ [9]. This result is consistent with the full recovery under load (rated current of $185 \mathrm{~A}$ ) of the superconducting tape during this time interval of a few seconds.

The energy density reached $534 \mathrm{~J} / \mathrm{cm}^{3}$, which is still lower than the critical value of $1,200 \mathrm{~J} / \mathrm{cm}^{3}$ [14]. The temperature profile was calculated considering the evolution of resistance value in YBCO tape, shown in Fig. 5. For this tape architecture, constituent materials, and at the maximum temperature of $360 \mathrm{~K}$, no degradation was observed in HTS tapes at current limitation [7].

\section{Fault Current Test of Resistive Modular Device}

The modular superconducting device unit (MSD) constituted 8 sectors comprising several stacks connected in series (YBCO 12 -mm width tape) with $21.5 \mathrm{~m}$ in length per sector, assembled
TABLE I

SPECIFICATION OF SFCL USING YBCO COATED CONDUCTOR

\begin{tabular}{cc}
\hline Item & Specification \\
\hline Phases & single-phase \\
Rated Voltage & $7.6 \mathrm{kV}$ \\
Rated current & $300 \mathrm{Arms}$ \\
Prospective short circuit current & $10 \mathrm{kArms}$ \\
Current after limitation & $2 \mathrm{kArms}$ \\
Limiting operation & $0.08 \mathrm{~s}$ to $1 \mathrm{~s}$ (with ACPR) \\
Parallel-connected elements & 1 to 2 \\
Series-connected elements & 8 \\
\hline
\end{tabular}

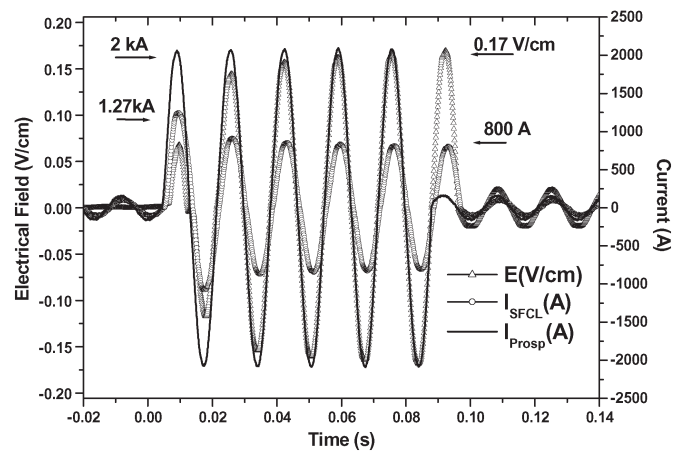

Fig. 6. Fault current test in SFCL for prospective current of $2 \mathrm{kA}$ with limiting current to $1.27 \mathrm{kA}$ (first peak) and $0.8 \mathrm{kA}$ after 5 cycles.

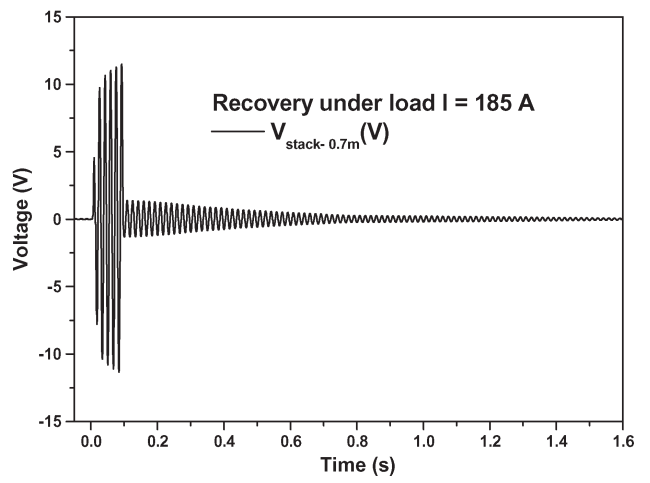

Fig. 7. Voltage waveform during fault current test of $2 \mathrm{kA}$ with recovery time less than $2 \mathrm{~s}$.

in anti-parallel arrangements to reduce the inductance, according with specification shown in Table I.

A reduced scale SFCL using 4.2-m length conductor $(6 \times$ $0.7 \mathrm{~mm}$ ) was built and tested using a step-down transformer as described before, with fault current level of $2 \mathrm{kA}$ applied during $80 \mathrm{~ms}$ and with time interval of $1.2 \mathrm{~s}$. The maximum electrical field reached $E=0.17 \mathrm{~V} / \mathrm{cm}$ for the prospective current of $2 \mathrm{kA}$ and $E=0.38 \mathrm{~V} / \mathrm{cm}$ for $2.5 \mathrm{kA}$ current.

Fig. 6 shows that the prospective current of $2 \mathrm{kA}$ was limited to $1.2 \mathrm{kA}$ (first peak) and to $0.8 \mathrm{kA}$ (after $80 \mathrm{~ms}$ ) corresponding to the limiting factor of 2.5 times.

The recovery time of less than $2 \mathrm{~s}$ was measured under load condition for a steady current of $185 \mathrm{~A}$ as shown in Fig. 7.

\section{Fault Current Test of RSCL Combined With Air Core Power Reactor}

The RSFCL built using $50 \mathrm{~m}$ of YBCO type $344 \mathrm{~S}$ with two 4-mm width tape in parallel, constituted by 24 sectors in series was designed for operation under $761 \mathrm{~V}$ and steady current of 


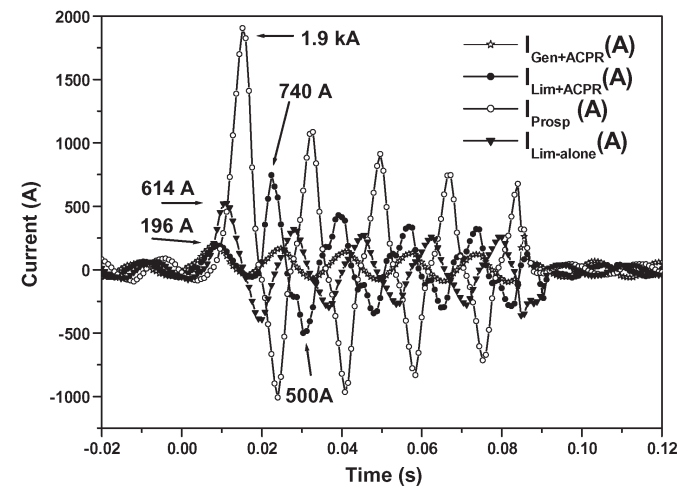

Fig. 8. Waveforms of current in the RSFCL combined with the ACPR for prospective current of $1.9 \mathrm{kA}$.

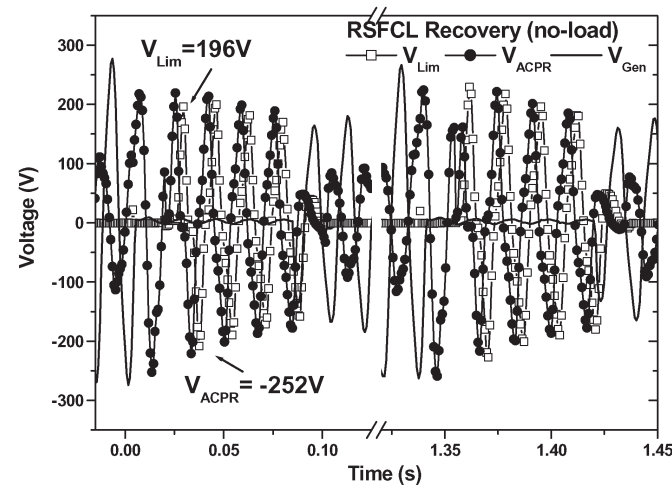

Fig. 9. Waveforms of voltages in the RSFCL combined with the ACPR during fault current of $1.9 \mathrm{kA}$.

150 A [15]. The combined limitation with RSFCL acting during $80 \mathrm{~ms}$ results in a very fast reduction of the prospective current (less than $4 \mathrm{~ms}$ ) and the extension of limitation period up to $1.2 \mathrm{~s}$ was guaranteed by adjacent channel assisted by ACPR. To confirm the very fast recovery of the superconducting device, a subsequent fault with $80 \mathrm{~ms}$ duration and time interval of $1.2 \mathrm{~s}$ (72 cycles) was applied. After the fault limitation by RSFCL, the maximum current bypassed to the ACPR is lower than $50 \%$ of the prospective fault value and the requirements for design became less stringent. It can be achieved with the selfinductance $L=4.5 \mathrm{mH}$ and the ratio $X / R=33.5$, connected in parallel during all times to the grid [3], [4].

The waveforms shown are the combined effect of RSFCL with an air-core reactor connected in parallel (Fig. 8). Together they can limit the prospective fault current value from $1.9 \mathrm{kA}$ down to $500 \mathrm{~A}$, corresponding to the limiting factor of 3.8 times.

After the insertion of RSFCL the total current increases from 175 up to $740 \mathrm{~A}$, just after it is reduced to $400 \mathrm{~A}$ achieving $270 \mathrm{~A}$ (4 cycles), which is a lower value than the limiting value because of the ACPR alone.

Fig. 9 shows the voltages waveforms during the fault current reaching $1.9 \mathrm{kA}$ for RSFCL combined with ACPR acting during the fault duration with $80 \mathrm{~ms}$ and subsequent fault current after a time interval of $1.2 \mathrm{~s}$. Recovery conditions were confirmed with RSFCL assisted by APCR under full load conditions, the voltage value in the RSFCL reaches $V_{\mathrm{Lim}}=196 \mathrm{~V}$ (lower than $V_{\mathrm{Lim}}=256 \mathrm{~V}$ and recovery time of $2.5 \mathrm{~s}$ without ACPR) during the first fault current limitation and the subsequent event, for a time interval greater than $0.9 \mathrm{~s} \mathrm{[13],} \mathrm{[15].}$

\section{CONCLUSION}

The waveforms showed the performance of RSFCL for two different geometry design using YBCO tapes with $2 \times 25 \mathrm{~m}$ length (4-mm width) for $1 \mathrm{kV}$ test-line and $4.2 \mathrm{~m}$ length (12-mm width) for $220 \mathrm{~V}$ test-line.

The RSFCL using a modular superconducting device built with 4-mm tape confirmed to act without degradation in a $220 \mathrm{~V}$ line for a prospective fault current of $1.9 \mathrm{kA}$, limiting the current to 614 A (limiting factor of 3.1 times).

The RSFCL built with 12-mm tape for a rated current of $185 \mathrm{~A}$ can limit in a $220 \mathrm{~V}$ line the prospective fault current value from $2 \mathrm{kA}$ to $1.2 \mathrm{kA}$ (first peak) and $800 \mathrm{~A}$ (after 5 cycles), corresponding to the limiting factor of 2.5 times. The combined system of RSFCL $(2 \times 4 \mathrm{~mm}$ width $)$ and ACPR for the prospective fault current of $1.9 \mathrm{kA}$, limiting the first peak current to $740 \mathrm{~A}$, after $8 \mathrm{~ms}$, reduced to $500 \mathrm{~A}$, which corresponds to a factor of 3.8 times

The RSFCL device was completely recovered for a subsequent fault with an interval of $1.5 \mathrm{~s}$ according to the switch breaker reclosing time used in the power grid system.

\section{REFERENCES}

[1] J. Bock et al., "HTS fault current limiters-First commercial devices for distribution level grids in Europe," IEEE Trans. Appl. Supercond., vol. 21, no. 3, pp. 1202-1205. Jun. 2011.

[2] S. Elschner et al., "ENSYSTROB-Design, manufacturing and test of a 3-phase resistive fault current limiter based on coated conductors for medium voltage application," Phys. C, Supercond., vol. 482, pp. 98-104. Nov. 2012.

[3] M. Noe, A. Hobl, P. Tixador, L. Martini, and B. Dutoit, "Conceptual design of a $24 \mathrm{kV}, 1 \mathrm{kA}$ resistive superconducting fault current limiter," IEEE Trans. Appl. Supercond., vol. 22, no. 3, Jun. 2012, Art. ID. 5600304

[4] A. Hobl et al., "Design and production of the ECCOFLOW resistive fault current limiter," IEEE Trans. Appl. Supercond., vol. 23, no. 3, Jun. 2013, Art. ID. 5601804

[5] W. Schmidt et al., "Investigation of YBCO coated conductors for fault current limiter applications," IEEE Trans. Appl. Supercond., vol. 17, no. 2, pp. 3471-3474, Jun. 2007.

[6] K. Nam, C. Lee, D. K. Park, T. K. Ko, and B. Y. Seok, "Thermal and electrical analysis of CC under AC overcurrent," IEEE Trans. Appl. Supercond., vol. 17, no. 2, pp. 1923-1926, Jun. 2007.

[7] M. J. Kim et al., "Determination of maximum permissible temperature rise considering repetitive over-current characteristics of YBCO coated conductors," IEEE Trans. Appl. Supercond., vol. 18, no. 2, pp. 660-663, Jun. 2008.

[8] W. Schmidt et al., "Design and test of current limiting modules using YBCO coated conductors," Supercond. Sci. Technol., vol. 23, no. 1, Jun. 2010, Art. ID. 014024.

[9] M. D. Ainslie et al., "Superconducting fault current limiter design using parallel-connected YBCO thin films," IEEE Trans. Appl. Supercond., vol. 19, no. 3, pp. 1918-1921, Jun. 2009.

[10] T. Nitta et al., "Tests for conceptual design of $6.6 \mathrm{kV}$ class Superconducting fault current limiter with YBCO thin film elements,"IEEE Trans. Appl. Supercond., vol. 19, no. 3, pp. 1964-1967, Jun. 2009.

[11] M. D. Ainslie, J. Baba, and T. Nitta, "Experimental study on an SFCL using series- connected YBCO thin films," J. Phys. Conf. Ser, vol. 97, no. 1, 2008, Art. ID. 012229.

[12] M. C. Ahn et al., "A study on the design of the stabilizer of coated conductor for applying to SFCL," IEEE Trans. Appl. Supercond., vol. 17, no. 2, pp. 1855-1858, Jun. 2007.

[13] S. E. Yang et al., "Experimental method for determining the recovery of superconducting fault current limiter using coated conductor in a power system," IEEE Trans. Appl. Supercond., vol. 18, no. 2, pp. 652-655, Jun. 2008.

[14] C. Schacherer, A. Kudymow, and M. Noe, "Dissipated energy as a design parameter of coated conductor for their use in resistive fault current limiters," J. Phys. Conf. Ser., vol. 97, no. 1, 2008, Art. ID. 012193.

[15] C. A. Baldan, J. S. Lamas, C. Y. Shigue, and E. R. Filho, "Test of a modular fault current limiter for $220 \mathrm{~V}$ line using coated conductor tapes with shunt protection," IEEE Trans. Appl. Supercond., vol. 21, no. 3, pp. 1242-1245, Jun. 2011. 